\title{
Left Behind: Surviving Suicide Loss
}

\author{
Sashi bhushan Kumar Gupta ${ }^{1} \odot$, Preeti Srinivasa ${ }^{2} \odot$, Mahesh Gowda ${ }^{3}$, Chandrashekar Muthylappa ${ }^{4}$
}

Indian Journal of Private Psychiatry (2020): 10.5005/jp-journals-10067-0066

\section{INTRODUCTION}

The book Left Behind is about people surviving suicide loss. The stigma around the topic is high, and people rarely share experiences regarding their loss. Nandini Murali is a gender and diversity researcher and practitioner and a communication professional. She also writes on Hindu dharma and is passionate about wildlife photography. In this book, she has shared her personal experience during the first three years after the death of her husband Dr TR Murali due to suicide. She highlights the need for validation of grief reaction to the survivors. Her journey on finding meaning in the pain guides readers and gives a ray of hope; however, the stigma and poor support from society remain prevalent.

\section{SUMMARY}

The guided use of selected books as an adjunct to treatment is applicable to patients in all stages of life and with a variety of problems. ${ }^{1}$

The book Left Behind: Surviving Suicide Loss written by Nandini Murali leaves a deep impact in our hearts. ${ }^{2}$ A senior psychiatrist Dr Raguram introduced this book to me. The author has shared her traumatic grief reaction to an unnatural death. She takes the reader through the overwhelming emotional turmoil for the first few years and its impact on her life. She writes, "A cocktail of toxic emotions throttled me-shame, fear, guilt, anger, and remorse. They would ambush me with the stealth and ruthlessness of an apex predator." She overcomes it with courage, compassion, and connection. Courage as she explains is "acceptance of one's vulnerabilities and is a key factor for authenticity." She shares how she was helped by her support groups and expresses her gratitude toward her family, friends, her two dogs (Mali and Minnal), her servants, people she met while exploring her pain, her spiritual guru, and suicide survivors she met in her journey of pain to purpose. This compassion of others with whom she felt connection was vital to explore herself. In her journey of seeking the meaning of the pain, she found spiritual practices and group therapy were similarly helpful. She courageously and scientifically explains the pain she underwent had its manifestation at her physical, emotional, and psychic grounds. She ferociously searched for help and experienced that the Shradh ceremony along with group therapy and psychiatric medicines have their part and were helpful. She believes every suicide is unique and not only family but significant others also go through grief and how stigma blocks the usual grief reaction. She expresses how the stigma around suicide is prevalent and her observation and experience that even mental health professionals lack adequate empathy. She comments on the magnitude of death by suicide by use of statistical data and how this problem has become a social issue. She talks about the need of training programs like suicide gatekeepers at a community level. One year of her husband's

\author{
${ }^{1-4}$ Department of Psychiatry, Spandana Nursing Home, Bengaluru, \\ Karnataka, India
}

Corresponding Author: Preeti Srinivasa, Department of Psychiatry, Spandana Nursing Home, Bengaluru, Karnataka, India, Phone: +91 9980734915, e-mail: preeti.snvs@gmail.com

How to cite this article: Gupta SBK, Srinivasa P, Gowda M, et al. Left Behind: Surviving Suicide Loss. Ind J Priv Psychiatry 2020;14(2):95-96.

Source of support: Nil

Conflict of interest: None

death, she launched SPEAK — an initiative to prevent suicide and promote mental health. She teaches from her experience and as an expert of language regarding communication skills to be used with suicide survivors "what to say and what not to say." She is a perfect example who searched for the meaning of suicide in her life. Her journey from turbulent ocean to shore guides the reader to introspect their emotional wreck at a painful situation and to deal with them directly without shame and secrecy. She shares experiences of other grieved families in different circumstances and finds that every suicide survivor needs validation of their emotional pain and unconditional support from society. The book offers much more than we expect and acts as a guide for people in grief. The book is based on her experiential introspection as well as massive research on the topic. Also she has substantiated the truth by personally meeting authors and other suicide survivors.

\section{Analysis}

As a psychiatrist, our learning is limited to treating patients with depression and averting suicide. Our helplessness in failure to prevent death by suicide in our patient induces guilt and doubts about our own judgment. However, very often we are not sensitized regarding survivors who have lost their near and dear. This book is enlightening in this perspective as she says the questions with which survivors grapple remain unanswered, ironically acceptance of this ambiguity is a milestone in the healing journey. Myself have witnessed a change in my mental health practice and have become more compassionate, empathetic, and sensitive to suicide survivors as compared to previously.

\section{Conclusion}

Indian literature lacks books on suicide survivors because of stigma and shame. The book is particularly helpful in the Indian context as the author shares the rites and rituals unique in Hindu dharma and her experience during those spiritual practices. Also she recommends modern therapy and the role of mental health professionals in taking care of survivors. 


\section{ORCID}

Sashibhushan Kumar Gupta @ https://orcid.org/0000-0002-4409-8164

Preeti Srinivasa @ https://orcid.org/0000-0001-9911-7927

\section{References}

1. Katz G, Watt JA. Bibliotherapy: the use of books in psychiatric treatment. Can J Psychiatry 1992;37(3):173-178. DOI: 10.1177/ 070674379203700305.

2. Nandini M. Left behind. Westland Publication Pvt Limited; 2021. 